\title{
Isolation and characterization of murine Kupffer cells and splenic macrophages
}

\author{
Timo L.M. ten Hagen ${ }^{*}$, Wim Van Vianen, Irma A.J.M. Bakker-Woudenberg \\ Department of Clinical Microbiology and Antimicrobial Therapy. Erasmus Unicersity Rotterdam, P.O. Box 1738, 3000 DR Rotterdam, \\ Netherlands
}

Received 13 June 1995; revised 30 November 1995: accepted 29 January 1996

\begin{abstract}
A method is described using counterflow centrifugation elutriation to isolate macrophages from murine liver and spleen. In this study three, size fractionated, macrophage populations were collected. Isolation resulted in a high yield of pure Kupffer cells (total of $10 \times 10^{6} / \mathrm{g}$ liver) and enrichment of splenic macrophages to $20 \%$. In addition to standard methods such as non-specific esterase staining, the isolated macrophages were also characterized by flow cytometry using specific monoclonal antibodies. In addition, a rapid flow cytometry method was introduced to determine the percentage of macrophages bases on autofluorescence. A strong correlation was found between the percentages of macrophages found by non-specific esterase staining and autofluorescence. Functional tests revealed differences between the isolated macrophages in terms of tumor necrosis factor- $\alpha$ (TNF- $\alpha$ ) production, oxygen metabolism and the production of nitric oxide. However. no significant differences in phagocytic activity was observed between the fractions. After two weeks of culture without the addition of antibiotics the cells still exhibited the above mentioned functions.
\end{abstract}

Keywords: Kupffer cell; Splenic macrophage; Isolation; Elutriation; Flow cytometry

\section{Introduction}

Isolation of Kupffer cells (KC) from mice by counterflow centrifugation elutriation (CCE) was de-

Abbreviations: $\mathrm{CCE}$, counterflow centrifugation elutriation: NSE, non-specific esterase staining; $\mathrm{AF}$, autofluorescence: $\mathrm{KC}$, Kuplfer cells: TNF- $\alpha$, tumor necrosis factor- $\alpha$; ROI, reactive oxygen intermediates; RNI, reactive nitrogen intermediates; DMEM. Dulbecco's modified Eagle medium; HBSS. Hanks' balanced salt solution: BSA, bovine serum albumin; WB, working buffer: MoAb, monoclonal antibody; FITC. fluorescein isothiocyanate: PI, propidium iodide: PMA, phorbol myristate acetate; cpm. counts per minute; NO, nitric oxide.

"Corresponding author. Tel.: +31(0)10-4087663: Fax: $+31(0) 10-4364730$. scribed in 1977 by Knook and Sleyster (1977). More recently the purification of $\mathrm{KC}$ from mice, using the same technique has been reported by other workers (Janousek et al., 1993). Macrophages isolated under these conditions prompted the examination of functional characteristics in vitro, and provide excellent starting material. Moreover, several methods have been described using $\mathrm{CCE}$ for the isolation of $\mathrm{KC}$ from rat liver. Some of these methods are widely used and provide researchers with a fairly pure, though heterogeneous population of $\mathrm{KC}$.

The isolation of splenic macrophages is far more difficult. The spleen possess different types of macrophages: the marginal zone macrophages, macrophages of the red pulp. the peri-arteriolar sheet, 
and the marginal metallophils, all of which possess different characteristics (Humphrey and Grennan, 1981). Relatively few methods have been described for the isolation of splenic macrophages (Buckley ct al., 1984; Ogle et al., 1994; Thompson et al.. 1983). Due to the size of the organ, and the percentage of macrophages in the spleen. the collection of reasonable numbers of macrophages from the murine spleen is not easy.

It is clear that the spleen comprises different types of macrophages. However, the findings of others suggest that in the rat also the $\mathrm{KC}$ population is heterogeneous (Hoedemakers et al., 1993). Our own studies on murine liver and spleen by flow cytometry have indicated different activities of macrophages in these organs, which is in accordance with the findings of other groups working with rat liver (Daemen et al., 1989. 1991; Hardonk et al., 1989; Itoh et al., 1992).

Here we describe a method using CCE for the isolation of macrophages from mouse liver and spleen. The tissue macrophages were isolated under sterile conditions using an autoclavable elutriation rotor, which facilitates culture without the use of antibiotics. The cells were characterized by flow cytometry using monoclonal antibodies which differentiate between the macrophages and other cells, and between the different types of macrophages. Autofluorescence was used as an indicator of the percentage of macrophages in the cell populations, and showed a high correlation with the standard non-specific esterase method. In addition, the cells were cultured under more physiological non-adherent conditions, without the addition of antibiotics.

\section{Materials and methods}

\subsection{Animals}

Specified pathogen-free, 13-15-week-old male C57B1/Ka mice were used (ITRI-TNO, Rijswijk, Netherlands). The experimental design and animal care were performed according to institutional guidelines.

\subsection{KC isolation}

Mice were anesthetized i.p. with Nembutal (Sanofi, Paris, France). A ventral midline incision exposed the peritoneal cavity, and a sterile 24-gauge Teflon cannula (introcan-w. 24G $\frac{3}{4}$. Braun Melsungen, Melsungen, Germany) was inserted into the vena porta. The liver was preperfused in situ with calcium-free Hanks' buffered salt solution $\left(\mathrm{Ca}^{2+}\right.$-free HBSS low endotoxin) (HyClone Laboratories, Logan, UT, USA) at $\mathrm{pH} 7.4$ and $30^{\circ} \mathrm{C}$, allowing the blood to flow from an incision in the vena cava inferior. After 2 min the wash solution was replaced by collagenase A solution $(0.163 \mathrm{U} / \mathrm{ml}$ in DMEM high glucose) (Boehringer Mannheim. Mannheim, Germany), and the liver was perfused at a flow rate of $5 \mathrm{ml} / \mathrm{min}$ for $30 \mathrm{~s}$ at $35^{\circ} \mathrm{C}$. After perfusion the liver was removed from the mouse and gently dispersed. Liver suspensions from eight mice were pooled and incubated under continuous agitation at $35^{\circ} \mathrm{C}$ for $10 \mathrm{~min}$ in $40 \mathrm{ml}$ collagenase solution as was used for the perfusion in $50 \mathrm{ml}$ polypropylene tubes. Hereafter all experiments were performed at $4^{\circ} \mathrm{C}$. The liver cell suspension was filtered through a nylon gauze $(212 \mu \mathrm{m})$ and taken up in $50 \mathrm{ml}$ HBSS containing $0.3 \%$ BSA (fraction $\mathrm{V}$, low endotoxin, Sigma, St. Louis, MO, USA) and $2 \mu \mathrm{g} / \mathrm{ml}$ DNase (low endotoxin, sterile, Boehringer Mannheim, Mannheim, Germany), and centrifuged at $400 \times g$ for $15 \mathrm{~min}$. This buffer is subsequently referred to as working buffer (WB). The pellet was taken up in $15.6 \mathrm{ml} \mathrm{WB}$ and mixed with $21 \mathrm{ml}$ NycoPrep (low endotoxin, sterile Nycodenz solution with a density of $1.150 \mathrm{~g} / \mathrm{ml}$ and osmolarity of 290 mosM. Nycomed Pharma. Oslo, Norway). The mixtures were transferred to three $15 \mathrm{ml}$ polypropylene tubes, and 1 $\mathrm{ml} \mathrm{WB}$ was layered on top of the mixture. Red blood cells and debris was sedimented by centrifugation at $1500 \times g$ over $15 \mathrm{~min}$. The cells in the interphase, which were mostly sinusoidal cells, were suspended in $50 \mathrm{ml} \mathrm{WB}$ and washed twice to remove Nycodenz by centrifugation at $400 \times g$ for $15 \mathrm{~min}$. The pellet was taken up in $5 \mathrm{ml} \mathrm{WB}$ and the cells further separated into various fractions by CCE using the autoclavable Beckman JE-5.0 elutriator rotor supplied with a Sanderson chamber (Beckman Instruments, Palo Alto, CA, USA). The cell suspension was introduced into the elutriator at a flow rate of 12 
$\mathrm{ml}$ WB per min, and the elutriator speed set to 3200 rpm. DNase was added to flow buffer $(2 \mathrm{mg} / 1$ in HBSS $/ 0.3 \% \mathrm{BSA}$ ) to prevent cell clumping in the elutriator chamber. Fractions of $100 \mathrm{ml}$ were collected at flow rates of $12,18,26,32$ and $50 \mathrm{ml} / \mathrm{min}$.

\subsection{Isolation of splenic macrophages}

Spleens were excised from anesthetized mice (see $\mathrm{KC}$ isolation) and spliced once with forceps. Organs from 15 mice were incubated under continuous agitation for $20 \mathrm{~min}$ at $35^{\circ} \mathrm{C}$ in $20 \mathrm{ml}$ collagenase A solution $(0.163 \mathrm{U} / \mathrm{ml}$ in HBSS). Thereafter the digest was gently pushed through a nylon gauze ( 88 $\mu \mathrm{m}$ ), and the cell suspension collected in $50 \mathrm{ml} \mathrm{WB}$ containing $0.5 \mathrm{IU}$ heparin. The cells were pelleted by centrifugation at $400 \times g$ for $15 \mathrm{~min}$, resuspended in $5.5 \mathrm{ml} \mathrm{WB}$ and mixed with $7 \mathrm{ml} \mathrm{Nycodenz}$. To prevent the cells in the interface from dehydration 1 $\mathrm{ml}$ WB was layered on top. The gradient was centrifuged for $15 \mathrm{~min}$ at $1500 \times \mathrm{g}$. The interface cells were transferred to a $50 \mathrm{ml}$ polypropylene tube containing WB and washed twice by centrifugation at $400 \times g$ for $15 \mathrm{~min}$. The pelleted cells were resuspended in $5 \mathrm{ml} \mathrm{WB}$ and introduced into the elutriator at a flow rate of $12 \mathrm{ml} \mathrm{WB}$ per min, and the rotor speed set at $3200 \mathrm{rpm}$. Fractions between 100 and $400 \mathrm{ml}$ were collected at flow rates of 12 , $18,24,36$ and $50 \mathrm{ml} / \mathrm{min}$.

\subsection{Culture of isolated $K C$ and splenic macrophages}

Isolated macrophages from fraction 3, 4, and 5 of the liver and spleen were brought to a density of $1.0 \times 10^{6}$ cells $/ \mathrm{ml}$ in DMEM high glucose culture medium (Gibco, Life Technologies, Gaithersburg, MD), supplemented with 15\% FCS (Gibco). The macrophages could be cultured in $5 \% \mathrm{CO}_{2}$ for up to 2 weeks at $37^{\circ} \mathrm{C}$ and in 96 well plates (MatTek,

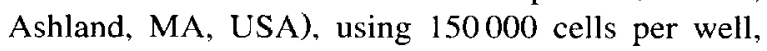
with continuous shaking at $110 \mathrm{rpm}$, or in plastic 96 well Falcon culture plates (Becton Dickinson, San Jose. CA).

\subsection{Characterization of isolated cell populations}

Flow cytrometric analysis was performed using of rat anti-mouse monoclonal antibodies (MoAb) as hybridoma culture supernatants. F4/80 (murine $\mathrm{M} \phi$ ) (Austyn and Gordon, 1980), MOMA-2 (murine M $\phi$ ) (Kraal et al., 1987), RA3-6B2 (B cells) (Coffman, 1982), KT3 (T cells) (Tomonari, 1988), 30G12 (general leukocyte marker) (Ledbetter and Herzenberg, 1979), and $Y 3$ a non-reacting negative control. All hybridoma supernatants were kindly provided by $\mathrm{P}$. Leenen and J. Voerman (Department of Immunology, Erasmus University, Rotterdam, Netherlands). $25 \mu \mathrm{l}$ cell suspension was mixed with $25 \mu$ l hybridoma supernatant and incubated at room temperature for $10 \mathrm{~min}$. Cell suspensions were washed three times with PBS containing 5\% FCS and $20 \mathrm{mM}$ sodium azide. Thereafter cells were incubated with an FITC-conjugated rabbit anti-rat antibody, $\left(\mathrm{F}\left(\mathrm{ab}^{\prime}\right)_{2}\right.$ fragment). Free conjugate was removed by washing as described above. The cell suspensions were examined on a FACScan and evaluated with Consort 30 software (Becton Dickinson, San Jose, CA).

\subsection{Determination of cell viability}

Cells were incubated after isolation with 50 $\mu \mathrm{g} / \mathrm{ml}$ propidium iodide (PI) (Sigma, St. Louis, MO, USA). Dead cells take up PI which intercalates with the DNA resulting in red fluorescent cells. The percentage of dead cells was determined by flow cytometry.

\subsection{Autofluorescence $(A F)$ as a quantitative marker of macrophage percentages in cell populations}

Macrophages are cells with a pronounced autofluorescent activity (Thorell, 1981). The percentage of autofluorescent cells $\left(\mathrm{AF}^{+}\right)$was evaluated by flow cytometry in the green emission range (FI1) (excitation $488 \mathrm{~nm}$, emission $520 \mathrm{~nm}$ ).

\subsection{Non-specific esterase (NSE) activity of the puri- fied cell fractions}

The purity of the cell fractions was verified on cytospin preparations after staining for NSE activity (Stroben, 1994). Briefly, cells were fixed with icecold formalin-acetone and incubated with pararosaniline/a-naphthyl butyrate. Cells were then counterstained with Gills hematoxylin and examined microscopically. 


\subsection{Quantitation of production of reactive oxygen (ROI) and nitrogen (RNI) intermediates}

Oxygen metabolism was examined by chemiluminescence $4 \mathrm{~h}$ after isolation. Briefly, $1 \times 10^{6}$ cells in $1 \mathrm{ml}$ were mixed with $100 \mu \mathrm{l} 5 \times 10^{-3} \mathrm{M}$ luminol (Sigma, St. Louis, MO, USA), and triggered with $100 \mu \mathrm{l} 5 \times 10^{-5} \mathrm{M}$ phorbol myristate acetate (PMA. Sigma, St. Louis, MO, USA). Chemiluminescence was measured using an AutoLumat LB953 (EG \& G Berthold, Wildbad, Germany). Nitrite production was measured using Griess reagents as reported by Stuehr and Nathan (1989) 6 days after isolation. Briefly, $1.5 \times 10^{5}$ macrophages in $150 \mu \mathrm{l}$ DMEM (without phenol red) supplemented with $10 \%$ FCS, were exposed to heat killed Klebsiella pneumoniae for 0,1 , 2 or $4 \mathrm{~h}$, and then $150 \mu \mathrm{l}$ of Griess reagents were added. Absorption at $570 \mathrm{~nm}$ was determined and compared with a standard curve prepared at the same time using known concentrations of sodium nitrite.

\subsection{Assessment of $T N F-\alpha$ production by $K C$}

After 6 days of culture $\mathrm{KC}$ were exposed to heat killed Klebsiella pneumoniae using a ratio of 15 bacteria per macrophage for $4 \mathrm{~h}$. TNF- $\alpha$ levels were determined in the culture medium using the WEHI 164 bioassay (Espevik and Nissen-Meyer. 1986).

\subsection{Phagocytic assay}

The microorganism use for phagocytosis was Candida albicans, grown for $24 \mathrm{~h}$ at $37^{\circ} \mathrm{C}$ in Sabouraud maltose broth (Oxoid, Basingstoke, Eng- land), washed three times with PBS and preserved on ice. KC fractions were cultured in 96 well plates at 200000 cells per well for 6 days in $200 \mu$ l DMEM supplemented with $15 \%$ FCS. After that cells were incubated with $C$. albicans using a ratio 50 microorganisms per macrophage. Non phagocytosed organisms were removed by washing the monolayers with PBS, and phagocytosis was examined microscopically after Diff-Quick staining.

\section{Results}

\section{I. Characterization of isolated $K C$}

Directly after separation by CCE, cell fractions were examined with respect to total cell number and the percentages of different cell types. Fraction 1 , collected at a flow rate of $12 \mathrm{ml} / \mathrm{min}$, only contained debris and no cells are present in this fraction. Fraction 2 contained large numbers of endothelial cells and KC. Routinely around $80 \times 10^{6} \mathrm{KC}$ were recovered in fraction 3 and around $20 \times 10^{6} \mathrm{KC}$ were recovered in fraction 4 , whereas $10 \times 10^{6} \mathrm{KC}$ were collected in fraction 5 at $50 \mathrm{ml} / \mathrm{min}$. A total of $10 \times 10^{7} \mathrm{KC}$ were collected from eight mice. The viability of these cells, as assessed by propidium iodide exclusion after isolation, appeared to be between 85 and $95 \%$.

As shown in Table 1, an increasing percentage of macrophages detected by NSE staining were collected by increasing flow rates: NSE positive cells increased from approximately $30 \%$ in the unseparated fraction to above $95 \%$ in fraction 5 . These

\footnotetext{
Fig. 1. Kupffer cells isolated by counterflow centrifugation elutriation were stained on slides with Diff Quick ( $A)$ or non-specific esterase $(B)$. Typical characteristics of the KC, membrane ruffling and large nucleus $(\mathrm{N})$ are shown in the Diff Quick staining (original magnification $1000 \times$ ). Kupffer cells are stained brown in the non-specific esterase reaction. A sample was taken from fraction 2 to enhance the differences in non-specific esterase staining (original magnification $400 \times$ ).
}

Fig. 2. Splenic macrophages isolated by counterflow centrifugation elutriation were stained on slides with (left panel) Diff Quick (2-5. numbers correspond with isolated fractions) or (right panel) non-specific esterase staining of fraction 5 only (original magnification $200 \times$ ). Macrophages are characterised by brownish staining in the cytoplasm (arrows), whereas granulocytes (PMN) do not stain with the non-specific esterase reaction (original magnification $400 \times$ ).

Fig. 8. Phagocytosis of Candida albicans by Kupffer cells in fractions 3.4 and 5. Kupffer cells in id monolayer were exposed to 20 microorganisms per macrophage for $10 \mathrm{~min}$. Fixed monolayers were stained with Diff Quick and 400 cells were examined per monolayer. Phagocytosed microorganisms (arrow head) and nucleus of Kupffer cells (arrow) are visible (original magnification $200 \times$ ). 

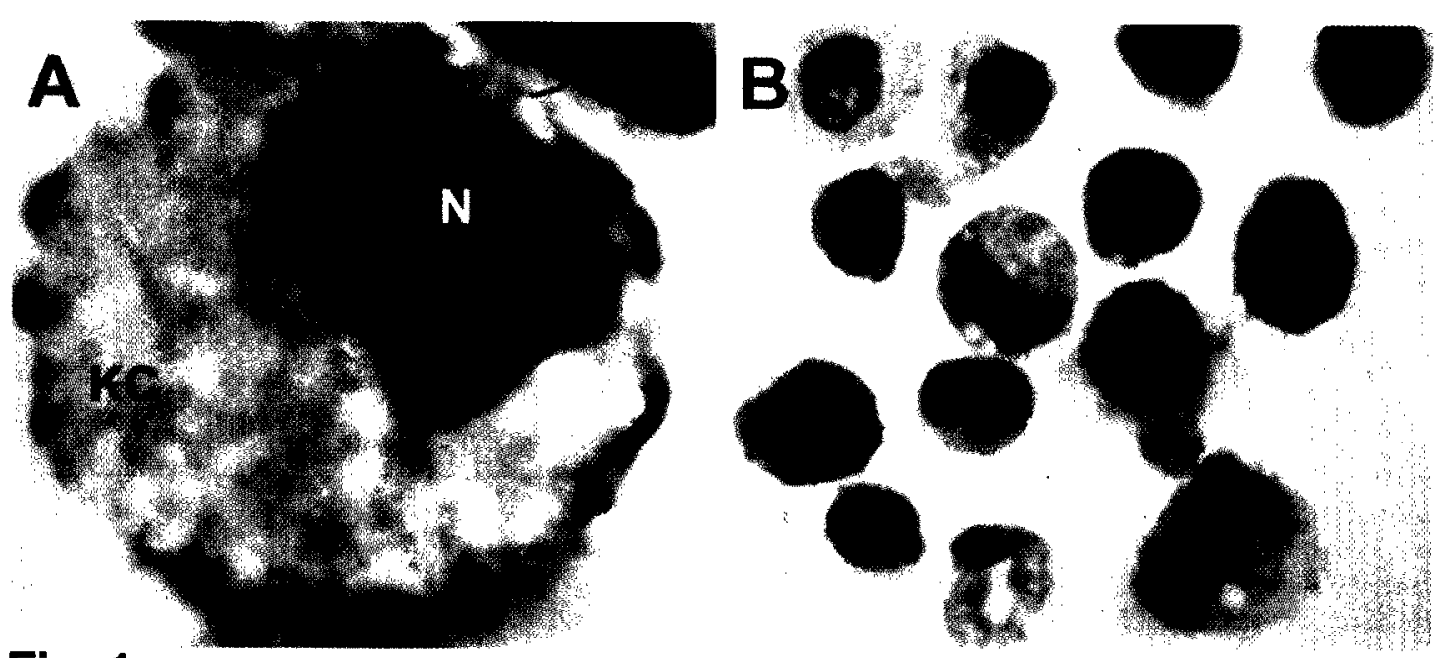

Fig. 1
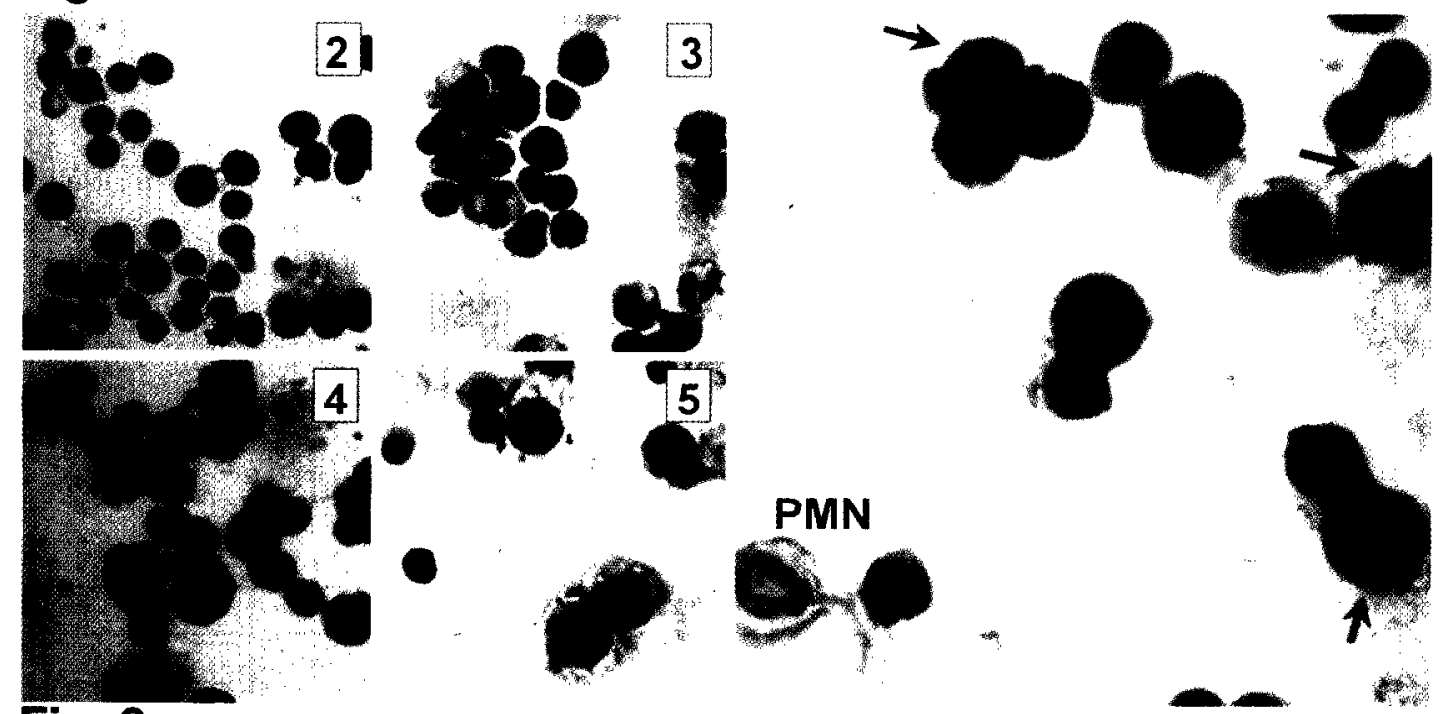

Fig. 2

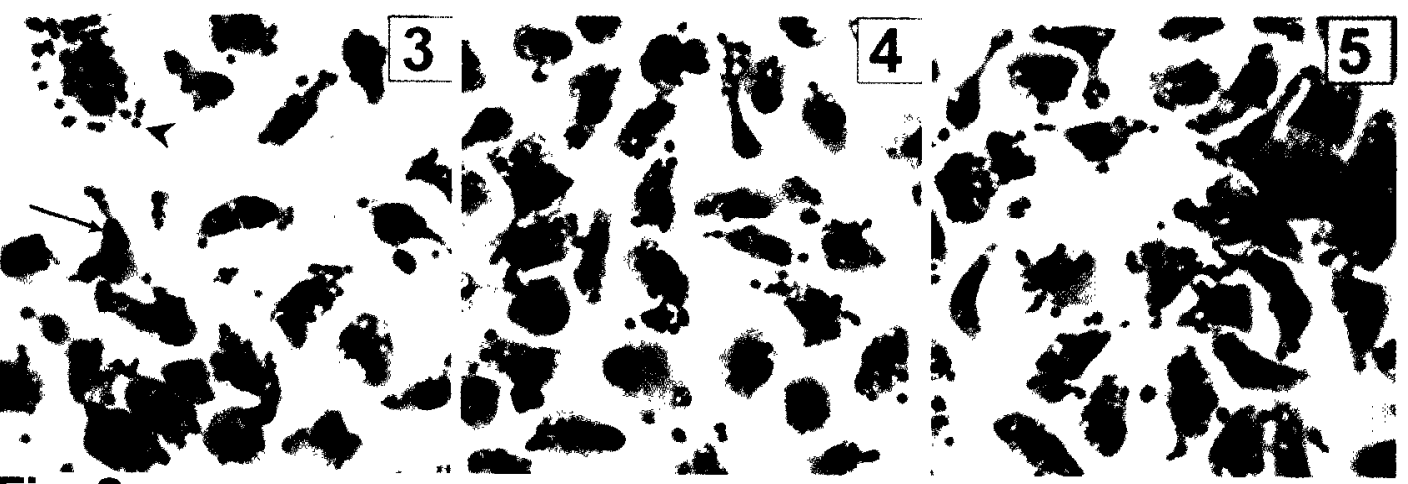

Fig. 8 
Table 1

Characteristics of Kupffer cells isolated from murine liver by counteflow elut ration centrifugation (CCE)

\begin{tabular}{|c|c|c|c|c|}
\hline & \multicolumn{4}{|c|}{ Kupffer cell fraction number } \\
\hline & 2 & 3 & 4 & 5 \\
\hline Fraction size $(\mathrm{ml})^{\mathrm{a}}$ & 100 & 100 & 100 & 100 \\
\hline Number of cells $\left(\times 10^{6}\right)$ & $57.3 \pm 17.2$ & $79.9 \pm 22.3$ & $21.4 \pm 6.4$ & $10.5 \pm 3.3$ \\
\hline \multicolumn{5}{|l|}{$\%$ positive cells } \\
\hline $\mathrm{NSE}^{\mathrm{c}}$ & $41.3 \pm 3.4$ & $80.9 \pm 1.2$ & $>92.5$ & $>95$ \\
\hline DQ & $17.9 \pm 1.3$ & $86.7 \pm 2.1$ & $>92.5$ & $>95$ \\
\hline $\mathrm{F} 4 / 80$ & $20.9 \pm 8.1$ & $50.2 \pm 8.1$ & $56.1 \pm 5.7$ & $47.3 \pm 3.7$ \\
\hline MOMA-2 & $32.1 \pm 4.2$ & $61.7 \pm 4.7$ & $68.2 \pm 4.8$ & $58.4 \pm 7.7$ \\
\hline $\mathrm{AF}$ & $51.9 \pm 9.7$ & $80.0 \pm 1.0$ & $88.9 \pm 4.4$ & $90.5 \pm 3.6$ \\
\hline
\end{tabular}

The data respresents the mean \pm 1 SD of at least six experiments.

"Fraction collected from the CCE.

${ }^{\mathrm{b}}$ Percentage of positive cells were determined for non-specific esterase activity and after Diff Quick staining on cell cytospins on slides by counting 400 cells. Percentage of F4/80 or MOMA-2 positive cells was determined by flow cytometry.

'NSE: non-specific esterase: DQ: Diff Quick; F4/80 and MOMA-2: macrophage-specific monoclonal antibodies; AF: autofluorescence.

results were confirmed by Diff-Quick staining, which clearly showed the presence of the majority of the macrophages in the last three fractions, recognizable by their asymmetric nucleus, vacuolized cytoplasm and membrane ruffling (Fig. 1).

Flow cytometry was also used to quantify $\mathrm{KC}$. Whereas only $50.2,56.1$ and $47.3 \%$ of the cells in fractions 3.4 and 5 respectively were found to be positive for F4/80, MOMA-2 recognized $61.7,68.2$ and $58.4 \%$ of the cells in the fractions 3,4 and 5 when FITC conjugated antibodies were used (Table 1). Using AF to evaluate the macrophage content of the fractions, $51.9 \%$ of the cells appeared to be positive in fraction 2, whereas fractions 3,4 and 5 contained 80.0 .88 .9 and $90.5 \% \mathrm{AF}^{+}$cells respectively.

Table 2

Characteristics of macrophages isolated from murine spleen by counterflow elutriation centrifugation (CCE)

\begin{tabular}{|c|c|c|c|c|}
\hline & \multicolumn{4}{|c|}{ Spleen cell fraction number } \\
\hline & 2 & 3 & 4 & 5 \\
\hline Fraction size $(\mathrm{ml})^{\mathrm{a}}$ & 100 & 400 & 200 & 200 \\
\hline $\begin{array}{l}\text { Number of cells }\left(\times 10^{6}\right) \\
\% \text { positive cells }{ }^{b}\end{array}$ & $952 \pm 188$ & $174 \pm 83.6$ & $78.7 \pm 34.7$ & $17.5 \pm 5.0$ \\
\hline $\mathrm{NSE}^{\mathrm{c}}$ & $<1$ & $4.0 \pm 0.3$ & $17.6 \pm 1.8$ & $18.3 \pm 1.9$ \\
\hline DQ & $<1$ & $10.3 \pm 1.1$ & $11.5 \pm 1.3$ & $14.0 \pm 1.5$ \\
\hline $\mathrm{F} 4 / 80$ & $2.2 \pm 0.4$ & $11.4 \pm 4.7$ & $21.8 \pm 4.5$ & $21.9 \pm 6.4$ \\
\hline MOMA-2 & $1.8 \pm 0.4$ & $6.4 \pm 1.4$ & $19.6 \pm 1.3$ & $19.4 \pm 6.3$ \\
\hline $\mathrm{AF}$ & $0.9 \pm 0.6$ & $4.9 \pm 3.3$ & $12.8+6.5$ & $14.3 \pm 3.7$ \\
\hline KT3 & $25.7 \pm 5.8$ & $16.0 \pm 0.2$ & $8.6 \pm 0.1$ & $21.5 \pm 0.4$ \\
\hline RA3-6B2 & $46.4 \pm 6.4$ & $41.9 \pm 0.1$ & $33.3 \pm 0.4$ & $34.7 \pm 0.7$ \\
\hline RB6-8C5 & $3.9 \pm 1.8$ & $19.1 \pm 7.8$ & $21.8 \pm 4.1$ & $21.6 \pm 3.2$ \\
\hline
\end{tabular}

The data respresents the mean \pm 1 SD of at least six experiments.

"Fraction collected from the CCE.

${ }^{b}$ Percentage of positive cells were determined for non-specific esterase activity and after Diff Quick staining on cell cytospins on slides by counting 400 cells. Percentage of F4/80, MOMA-2, KT3, RA3-6B2. and RB6-8C5 positive cells was determined by flow cytometry.

"NSE: non-specific esterase: DQ: Diff Quick: F4/8t) and MOMA-2: macrophage-specific monoclonal antibodies: AF: autofluorescence: KT3: T cell; RA3-6B2: B cell-, and RB6-8C5: granulocyte-specific monoclonal antibodies. 

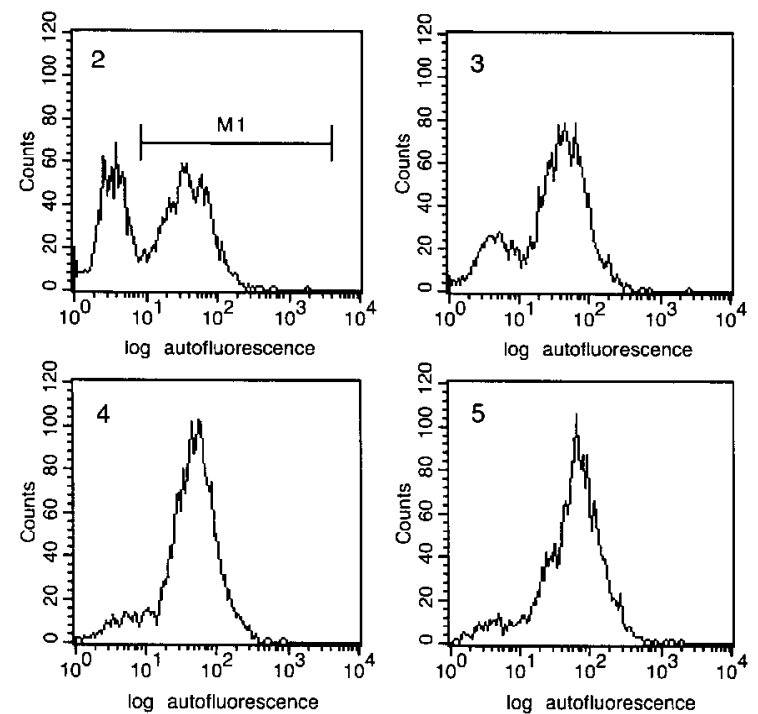

Fig. 3. Analysis of Kupffer cell fractions 2-5. collected by counterflow centrifugation elutriation, by flow cytometry using autofluorescence to positively identify macrophages. Cells in the area $\mathrm{Ml}$ are $\mathrm{AF}^{+}$. The graph numbers correspond to the fraction numbers collected. The graphs are representative of at least six experiments.

\subsection{Characterization of isolated splenic macrophages}

Fraction 1 , collected at $12 \mathrm{ml} / \mathrm{min}$ did not contain any cells. Splenic macrophages were present in
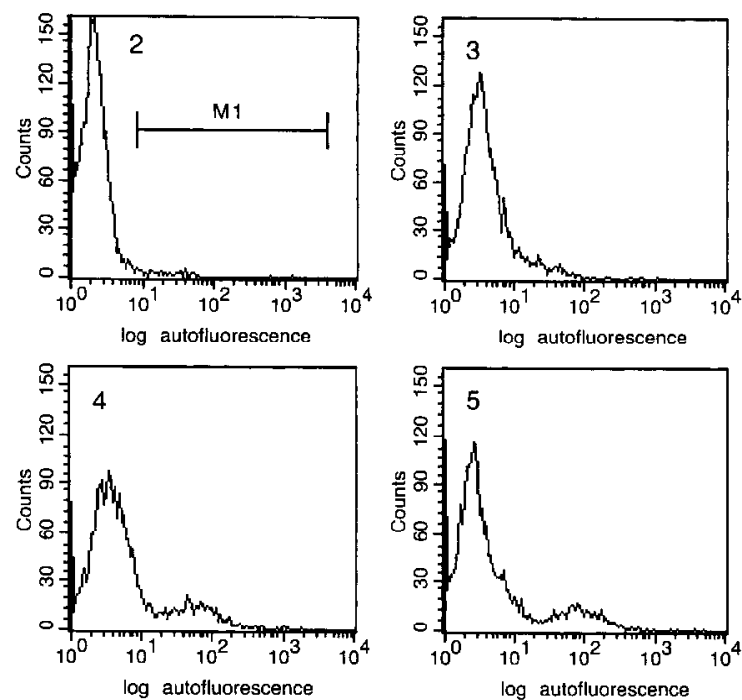

Fig. 4. Analysis of spleen macrophage fractions $2-5$, collected by counterflow centrifugation elutriation, by flow cytometry using autofluorescence to positively identify macrophages. Cells in the area $\mathrm{M} 1$ are $\mathrm{AF}^{+}$. The graph numbers correspond to the fraction numbers collected. The graphs are representative of at least six experiments

fractions 3,4 and 5 , as confirmed by cytospin preparations followed by Diff-Quick or NSE staining (Fig. 2). Less then $1 \%$ of the unseparated cells were found to be NSE positive. Flow cytrometric analysis revealed that $11.4,21.8$ and $21.9 \%$ of the cells were

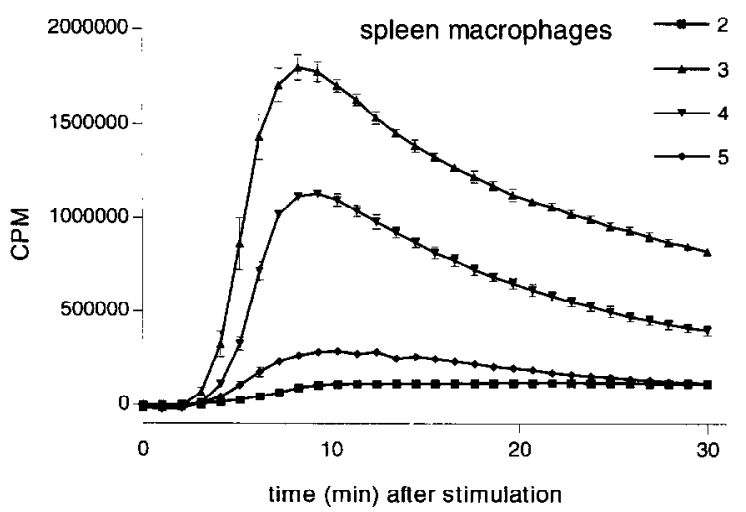

Fig. 5. Chemiluminescence of Kupffer cell fractions 2-5 and spleen macrophage fractions 2-5 in suspension, collected by counterflow centrifugation elutriation, with PMA used as trigger. Chemiluminescence of unstimulated cells was below the treshold of detection. The data respresent the mean $\pm 1 \mathrm{SD}$ of three experiments. 


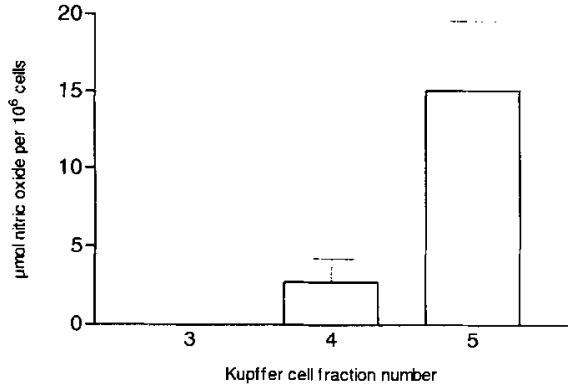

Fig. 6. Production of nitric oxide by Kupffer cell fractions 3. 4 and $54 \mathrm{~h}$ after stimulation with heat killed Klebsiella pneumoniae. Production of NO by unstimulated cells was below the detection level. The data respresents the mean $\pm 1 \mathrm{SD}$ of three experiments.

positive for $\mathrm{F} 4 / 80$ whereas $6.4,19.6$ and $19.4 \%$ of the cells stained with MOMA-2 in fractions 3, 4 and 5 respectively (Table 2 ). The percentages of $\mathrm{AF}^{+}$ cells determined by flow cytometry in spleen fractions $2,3,4$ and 5 were $<1,4.9,21.8$ and $21.6 \%$ respectively.

The spleen is mostly composed of T and B cells. We therefore examined the percentage T cells (KT3) and B cells (RA3-6B2) in the different fractions. Neither cell type was removed effectively from the cell populations by CCE (Table 2). The number of $T$ cells in the various fractions did not differ significantly, whereas the percentage of B cells decreased from $63.1 \%$ before CCE to $44.3 \%$ in fraction 3 . Granulocytes (RB6-8C5) also exhibit phagocytic activity and produce oxygen intermediates. Therefore, the percentage of these cells in the fractions was evaluated. It appeared that the percentage of granulocytes in the spleen cell fractions increased after CCE compared to the complete cell suspension $(4.6 \%$ before and $20 \%$ granulocytes after CCE).

The percentages of cells positive for NSE and positive in the Diff-Quick staining in both the $\mathrm{KC}$ and splenic macrophage isolations appeared to correlate closely with the percentages of cells exhibiting AF activity. As can be seen in Table 1 the percentage of $\mathrm{AF}^{+}$cells increased from 51.9 to $90.5 \%$ between $\mathrm{KC}$ fractions 2 and 5 . NSE positive cells increased from 41.3 to $>95 \%$ (correlation coefficient, $r^{2}$ 0.998). A similar correlation was noted with splenic macrophages with an increase from 0.9

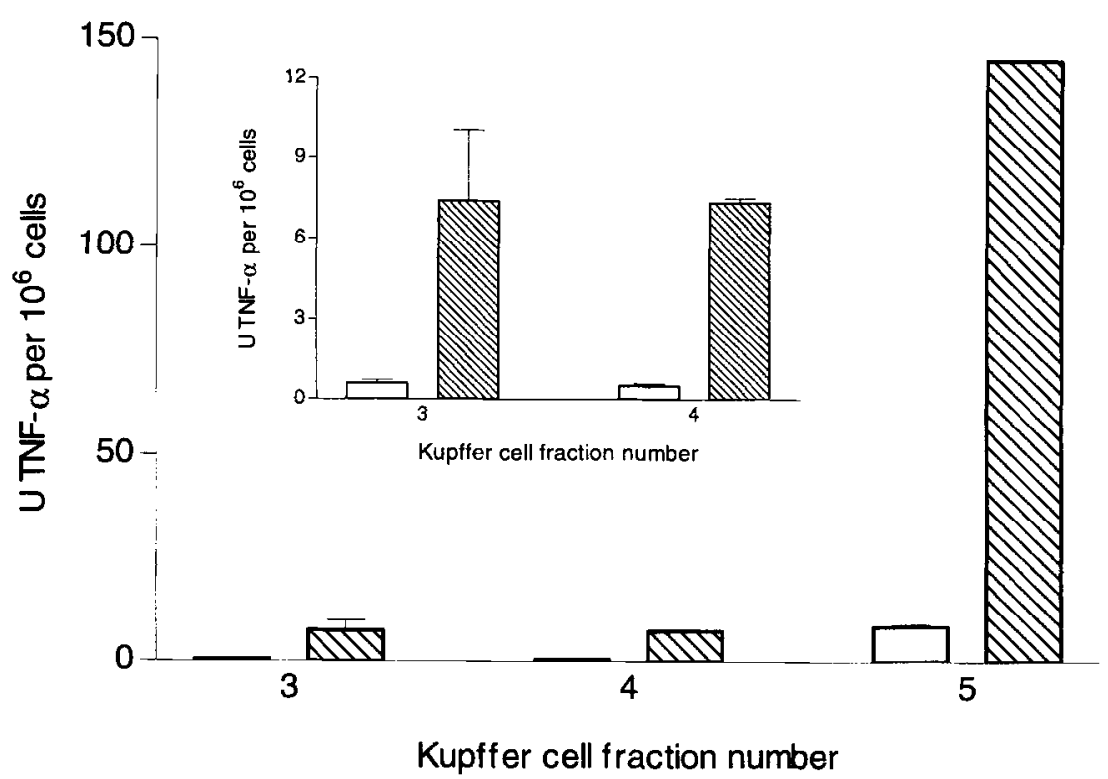

Fig. 7. Production of TNF- $\alpha$ by Kupffer cell Fractions 3,4 and $512 \mathrm{~h}$ after stimulation with heat killed Klebsiella pneumoniae (hatched bars) or with medium alone (open bars). The data respresent the mean \pm 1 SD of three experiments. 
to $14.3 \%$ for $\mathrm{AF}$ and $<1$ to $18.3 \%$ for NSE $\left(r^{2}\right.$ $0.989)$. Figs. 3 and 4 illustrate how the percentage of $\mathrm{AF}^{+}$cells (macrophages) can be determined by flow cytometry for both liver and spleen.

In our hands more macrophages could be isolated from liver and spleen after the addition of DNase and we did not find a deleterious effect of DNase on cell viability in contrast to others (Janousek et al., 1993). In the absence of DNase the isolation procedure resulted in cell clumping, a low yield, and especially for the splenic macrophages in very irreproducible results (Sanderson and Bird, 1977).

Cells were examined for oxygen metabolism in suspension after stimulation with PMA. Fig. 5 shows that KC fractions exhibited different levels of oxygen metabolism. Fraction 2 had little metabolic activity (53000 peak cpm), whereas fraction 3 was most active (470000 peak cpm). Oxygen metabolism decreased again in fractions 4 and 5 (respectively 290000 and 190000 peak cpm). This activity appeared to be superoxide dependent: in all fractions chemiluminescence was decreased by around $70 \%$ following the addition of superoxide dismutase (data not shown).

Oxygen metabolism in the spleen cell fractions was much higher compared to the KC cells (Fig. 5). Fraction 3 showed strong activity (1 800000 peak $\mathrm{cpm})$, which was decreased in fraction $4(1130000$ peak cpm). Fractions 2 and 5 were characterized by low oxygen metabolism compared to the other fractions (110000 and 290000 peak cpm respectively). Because of the impurity of the spleen cell fractions and the low yield of splenic macrophages further functional tests were performed only with $\mathrm{KC}$.

The production of significant amounts of NO could only be measured in the culture supernatants of $\mathrm{KC}$ fraction 5 after stimulation with heat killed Klebsiella pneumoniae. $\mathrm{KC}$ in fraction 5 produced around $15 \mu \mathrm{mol} \mathrm{NO}$ per $10^{6}$ cells, whereas there was no detectable NO production in supernatants of fraction 3 (Fig. 6).

$\mathrm{KC}$ purified by CCE and cultured for 6 days were assayed for TNF- $\alpha$ production. Fraction 5 appeared to produce high levels of TNF- $\alpha$ (150 U per $10^{6}$ cells), whereas fractions 3 and 4 produced small but significant amounts (around $8 \mathrm{U}$ TNF- $\alpha$ per $10^{6}$ cells), after triggering with heat killed Klebsiella pneumoniae (Fig. 7).
All KC fractions exhibited strong phagocytic activity when exposed to Candida albicans. After 10 min of exposure almost $100 \%$ of the cells contained microorganisms. $\mathrm{KC}$ appeared to phagocytose around 20 microorganisms per macrophage when exposed for $10 \mathrm{~min}$ to 50 microorganisms per macrophage (Fig. 8). We observed a TNF- $\alpha$ and RNI production of approximately $60 \%$ after two weeks of culture, and all cells still phagocytosed $C$. albicans at that time point (data not shown).

\section{Discussion}

In most publications related to the isolation of resident macrophages from liver, $\mathrm{KC}$ are considered to be a single population (Heuff et al., 1993, 1994; Janousek et al., 1993; Knook and Sleyster, 1977; Ogle et al., 1994; Sanders and Soll, 1989). Only few groups have described the isolation of different fractions of macrophages from the liver of the rat (Daemen et al., 1989, 1991; Hardonk et al., 1989; Itoh ct al., 1992; Hoedemakers et al., 1993) and from spleen (Thompson et al., 1983). Cell populations of rat liver macrophages have been functionally examined with emphasis on tumor cytotoxicity and response to immunomodulator treatment (Daemen et al., 1989. 1991; Hardonk et al., 1989; Hoedemakers et al., 1993) The findings of others in rats and our own (unpublished) observations in vivo in mice, led us to the isolation of subgroups of macrophages from liver and spleen in orders to study the heterogeneity of mouse macrophages. In the present study a method is described in which murine $\mathrm{KC}$ and splenic macrophages are isolated and fractionated into three groups of macrophages depending on their size by CCE. It appeared that these cells not only differed in their size but were also characterized by a completely different range of activities.

Three fractions of $\mathrm{KC}$ were isolated with purities ranging from 81 to $>95 \%$ as estimated with NSE and this was confirmed by autofluorescence. However, lower percentages were found when specific MoAb were used (F4/80 50.2-56.1\% and MOMA-2 61.0-68.2\%). This discrepancy was most probably due to (1) the low expression of the surface markers of the macrophages and (2) to the specificity of the $\mathrm{MoAb}$ resulting in detection of only a subgroup of 
the macrophages. Furthermore the phagocytosis of C. albicans suggested that the fractions contained large numbers of macrophages. The overall yield was around $10 \times 10^{7}$ cell per isolation, which means that around $1 \times 10^{7} \mathrm{KC}$ were isolated per gram mouse liver. Fraction 3 contained small KC, fraction 5 contained large, and fraction 4 contained intermediate sized $\mathrm{KC}$. The isolated $\mathrm{KC}$ in the different fractions exhibited different metabolic activities. The production of ROI by $\mathrm{KC}$ could not be explained by the presence of granulocytes, because such cells were not detected using our screening methods. However, these findings contrast with those of Lepay et al. (1985). who found $\mathrm{KC}$ to be deficient in production of ROI. It is possible that this group selectively isolated large $\mathrm{KC}$ which exhibit only very low ROI production.

Although fraction 3 cells showed strong oxygen metabolism, they produced only very small amounts of TNF- $\alpha$ or nitric oxide after stimulation. Fraction 4 was comparable to fraction 3 , but fraction 5 , which was composed of large $\mathrm{KC}$, showed a significant production of TNF- $\alpha$ and nitric oxide. These results are comparable with those of Decker et al. (1989) and Ogle et al. (1994), suggesting that their KC population contained predominantly large $\mathrm{KC}$. However, Shimauchi et al. (1993) reported that KC produced much lower amounts of TNF- $\alpha$, which might be explained by a $\mathrm{KC}$ population composed of predominantly small or intermediate cells. We found that an improved separation could be obtained between the KC fractions when the rotor speed was set to $3200 \mathrm{rpm}$, compared to the generally used setting of $2400 \mathrm{rpm}$ (unpublished observations). We also used this setting for splenic macrophage isolation.

The isolation of murine splenic macrophages proved far more difficult. Various fractions were collected by $\mathrm{CCE}$ and increasing percentages of macrophages from $4 \%$ up to $11.4 \%, 21.8 \%$, and $21.9 \%$ respectively were obtained in the last three fractions as detected with MoAb F4/80. Flow cytometry using the MOMA-2 antibody yielded comparable percentages of $6.4,19.6$, and 19.4 respectively. These finding are in agreement with Buckley et al. (1984), who isolated one fraction from human spleen with $28 \%$ mononuclear phagocytes, but they differ from those of Thompson et al. (1983). In the latter study various fractions were isolated but the percentage of macrophages ranged from 3 to $5.2 \%$. In the spleen MoAb F4/80 predominantly recognizes red pulp macrophages, whereas MOMA-2 binds to (mature) white pulp macrophages, as well as to red pulp macrophages (review by Leenen et al,, 1994).

Production of ROI by splenic macrophages in the different fractions was similar to that observed with the $\mathrm{KC}$ fractions. However, the interpretation of these results are hampered by the presence of granulocytes in the fractions, which exhibit strong oxygen metabolism. It appeared that the percentage of granulocytes in the last three fractions were practically the same, which suggests that the percentage of granulocytes does not account for the differences in ROI production. It is unclear whether the differences in metabolic activity in the three fractions were related to differences in the macrophages, or whether size separation of granulocytes also occurs resulting in granulocytes with different oxygen metabolism.

\section{References}

Austyn. J.M. and Gordon. S. (1980) F4/80, a monoclonal antibody directed specifically against the mouse macrophage. Eur. J. Immunol. 11, 805 ,

Buckley, P.J., Beelen, R.H.J.. Burns, J., Beard, C.M.. Dickson, S.A. and Walker W.S. (1984) Isolation of human splenic macrophages and lymphocytes by countercurrent centrifugal elutriation. J. Immunol. Methods 66, 201.

Coffman, R.L. (1982) Surface antigen expression and immunoglobulin gene rearrangement during mouse pre- $B$ development. Immunol. Rev. 69. 5.

Daemen, T., Veninga, A., Roerdink, F.H. and Scherphof. G.L. (1989) Endocytic and tumoricidal heterogeneity of rat liver macrophage populations. Sel. Cancer Ther. 5, 157.

Daemen, T., Veninga. A.. Regts. J. and Scherphof. G.L. (1991) Maintenance of tumoricidal activity and susceptibility to reactivation of subpopulations of rat liver macrophages. J. Immunother. 10. 200.

Decker, T., Lohman-Matthes. M.-L.. Karck. U.. Peters, T. and Decker. K. (1989) Cooperative study of cytotoxicity, tumor necrosis factor, and prostaglandin release after stimulation of rat Kupffer cells, murine Kupfer cells, and murine inflammatory liver macrophages. J. Leukoc. Biol. 45, 139.

Espevik, T. and Nissen-Meyer, J. (1986) A highly sensitive cell line, WEHI 164 clone 13, for measuring cytotoxic factor/tumor necrosis factor from human monocytes. J. Immunol. Methods 95, 99.

Hardonk. M.J., Van Goor, H., Scherphot. G,L. and Daemen. T. (1989) Functional heterogeneities between large and small 
Kupffer cells. In: E. Wisse, D.L. Knook and K. Decker (Eds.). Cells of the Hepatic Sinusoid, Vol. 2, Proc. Fourth Int. Syrnp. Cells Hepatic Sinusoid. Titisee 1989. The Kupffer Cell Foundation, Leiden, Netherlands, p. 434.

Heuff, G., Steenbergen, J.J.E., Vandeloosdrecht, A.A., Sirovich, I. Dijkstra, C.D., Meyer, S. and Beelen, R.H.J. (1993) Isolation of cytotoxic Kupffer cells by a modified enzymatic assay - A methodological study. J. Immunol. Methods 159, 115.

Heuff. G., Meyer. S. and Beelen. R.H.J. (1994) Isolation of rat and human Kupfer cells by a modified enzymatic assay. I. Immunol. Methods 174, 61 .

Hoedemakers, R.M., Vossebeld. P.J., Daemen, T. and Scherphof, G.L. (1993) functional characteristics of the rat liver macrophage population after single intravenous injection of liposome-encapsulated muramyl peptides. J. Immunother. 13. 252.

Humphrey. J.H. and Grennan. D. (1981) Different macrophage populations distinghised by means of fluorescence polysaccharides. Recognition and properties of marginal-zone macrophages. Eur. J. Immunol, 11, 221.

Itoh. Y.. Okanoue, T., Morimoto, M., Nagao, Y., Mori, T., Hori. N.. Kagawa, K. and Kashima, K. (1992) Functional heterogeneity of rat liver macrophages: Interleukin- 1 secretion and Ia antigen expression in contrast with phagocytic activity. Liver 12, 26.

Janousek. J.. Strmen. E. and Gervais. F. (1993) Purification of murine Kupffer cells by centrifugal elutriation. J. Immunol. Methods 164, 117.

Knook, D.L. and Slcystcr, E.C. (1977) Preparation and characterization of Kupffer cells from rat and mouse liver. In: E. Wisse and D.L. Knook (Eds.), Kupffer Cells and Other Liver Sinusoidal Cells; Proc. Int. Kupffer Cell Symp., Noordwijkerhout, 1977. Elsevier, New York, p. 273.

Kraal, G. Rep. M. and Janse. M. (1987) Macrophages in T and B cell compartments and other tissue macrophages recognized by monoclonal antibody MOMA-2. An inmunohistochemical study. Scand. J. Immunol. 26. 661.

Ledbetter, J.A. and Herzenberg, L.A. (1979) Xenogeneic monoclonal antibodies to mouse lymphoid differentiation antigens. Immunol. Rev. 47, 63.

Leenen, P.J.M., De Bruijn, M.F.T.R., Voerman, J.S.A., Campbell. P.A. and Van Ewijk, W. (1994) Markers of mouse macrophage development detected by monoclonal antibodies. J. Immunol. Methods 174, 5.

Lepay, D.A.. Nathan. C.F., Steinman, R.M., Murray, H.W. and Cohn, Z.A. (1985) Murine Kupffer cells. Mononuclear phagocytes deficient in the generation of reactive oxygen intermediates. J. Exp. Med. 161, 1079.

Ogle, C.K., Wu, J.Z., Ma, X.L., Szczur, K., Alexander, J.W. and Ogle, J.D. (1994) Heterogeneity of Kupffer cells and splenic. alveolar, and peritoneal macrophages for the production of TNF, IL-1, and IL-6. Inflammation 18, 523.

Sanders, J.M. and Soll, A.H. (1989) Cell separation by elutriation: Major and minor cell types from complex tissues. Methods Enzymol. 171, 482.

Sanderson, R.I. and Bird, K.E. (1977) Cell separations by counterflow centrifugation. Methods Cell Biol. 15, 1.

Shimauchi, Y.. Tanaka, M., Yoshitake. M.. Shimada. M.. Sato, K., Kuromatsu, R, Tanaka, S., Kumashiro, R., Sakisaka, S. and Tanikawa. K. (1993) Functional differences between rat Kupffer cells and splenic macrophages. In: K. Decker, D.L. Knook and E. Wisse (Eds.), Cells of the Hepatic Sinusoid, Vol. 4, Proc. Sixth Int. Symp. Cells Hepatic Sinusoid. Antwerp, 1992. The Kupffer Cell Foundation, Leiden, Netherlands, p. 198.

Stroben, W. (1994) Wright-Giemsa and nonspecific esterase staining of cells. In: J.E. Coligan, A.M. Kruisbeek, D.H. Margulies, E.M. Shevach and W. Strober (Eds.), Current Protocols in Immunology, Vol. 2. Greene Publishing Associates, and John Wiley and Sons, New York. p. A3.5.

Stuchr. D.J. and Nathan, C.F. (1989) Nitric oxide a macrophage product responsible for cytostasis and respiratory inhibition of tumor target cells. J. Exp. Med. 169, 1543.

Thompson, C.B., Ryan, J.J., Sieckmann, G., Finkelman, F.D., Mond. J.J. and Scher. I. (1983) A method for size separation of murine spleen cells using counterflow centrifugation. J. Immunol. Methods 63, 299.

Thorell, B. (1981) Flow cytrometric analysis of cellular endogenous autofluorescence simultanously with emission from exogenous fluorochromes, light scatter, and absorption. Cytometry 2,39 .

Tomonari, K. (1988) A rat antibody against a structure functionally related to the mouse $\mathrm{T}$-cell receptor/T3 complex. Immunogenetics 28,455 . 